\title{
ANÁLISIS DE SECCIONES DELGADAS DE MATERIAS PRIMAS LÍTICAS PROVENIENTES DE LA LOCALIDAD ARQUEOLÓGICA LA MARÍA, MESETA CENTRAL DE SANTA CRUZ, ARGENTINA
}

\author{
Fabiana Skarbun ${ }^{1}$ y Gerardo Páez ${ }^{2}$ \\ ${ }^{1}$ Facultad de Ciencias Naturales y Museo. Universidad Nacional de La Plata. E-mail: fskarbun@fcnym.unlp.edu.ar \\ ${ }^{2}$ Instituto de Recursos Minerales (INREMI) y CONICET. E-mail: marduk_paez@yahoo.com.ar.
}

Presentado el: 08/12/2011 - Aceptado 29/02/2012

\section{Resumen}

En este trabajo se analiza la litología de las materias primas silíceas con potencialidad para la talla, que provienen de distintas fuentes de aprovisionamiento de la localidad arqueológica La María. La misma se localiza en el centro del Macizo del Deseado, Santa Cruz, Argentina y sus coordenadas geográficas se encuentran comprendidas entre $48^{\circ} 24^{\prime} S$ y $48^{\circ} 35^{\prime} S$ y $68^{\circ} 47^{\prime} \mathrm{O}$ y $68^{\circ} 56^{\prime} \mathrm{O}$. Para analizar los distintos tipos litológicos se examinaron secciones delgadas de rocas de calidad regular a muy buena para la talla. Se busca, por un lado, indagar la variabilidad litológica intra e interfuente. Por otro lado, se plantea caracterizar microscópicamente los tipos de materias primas más frecuentemente identificados en las fuentes -los mismos han sido reconocidos a nivel macroscópico en los sitios arqueológicos del área-. Por último, se evalúa la posibilidad de realizar en la región estudios de procedencia de los restos arqueológicos confeccionados en estas rocas.

Palabras claves: Cortes delgados, Fuentes de recursos líticos, Estrategias tecnológicas, Patagonia.

\begin{abstract}
This paper analyzes the lithology of siliceous raw materials from different sources of La Maria archaeological locality, which are potentially knappable. The locality is placed at the center of the Deseado Massif, Santa Cruz, Argentina, between $48^{\circ} 24^{\prime} S$ and $48^{\circ} 35^{\prime} S$ and $68^{\circ} 47^{\prime} W$ and $68^{\circ}$ $56^{\prime} W$. In order to analyze the different lithological types, thin sections of regular to good knapping quality rocks are examined. The main goal is to inquire about intra and intersource lithological variability. Furthermore, the microscopic characterization of the raw material types most frequently identified in the sources is performed -these rocks have been recognized macroscopically at regional archaeological sites-. Finally, the possibility of developing provenience studies on lithic artifacts made on these raw materials is evaluated.
\end{abstract}

Keywords: Thin section, Lithic sources, Technological strategies, Patagonia.

\section{Introducción}

El Macizo del Deseado se caracteriza por un extenso evento volcánico de edad Jurásico media a superior (Pankhurst et al. 1998), al que se asocia un importante hidrotermalismo que ha originado numerosos campos de vetas y extensas zonas de alteración hidrotermal 
(Schalamuk et al. 1997). En este contexto, la localidad arqueológica La María presenta una amplia distribución de materias primas silíceas de regular a muy buena calidad para la talla (sensu Aragón y Franco 1997), las cuales fueron utilizadas desde las primeras ocupaciones humanas durante el Pleistoceno final, tanto a nivel local como regional (Cattáneo 2004; Frank et al. 2007; Hermo 2008; Paunero 2001; Paunero et al. 2005; Skarbun 2009).

La selección y obtención de materias primas es un primer paso en la secuencia de producción de artefactos dentro de una determinada forma de organización de la tecnología lítica (Andrefsky 1994; Bleed 1986; Nelson 1991). Este trabajo se elabora en el marco de distintos análisis que se están llevando a cabo para conocer la estructura local de los recursos líticos de la localidad arqueológica La María. Los mismos tienen el fin de comprender las estrategias que implementaron los grupos humanos que ocuparon la región en el pasado para la producción de sus artefactos líticos (Frank et al. 2007; Frank et al. 2011; Skarbun 2011 a y b).

De esta manera, los estudios específicos sobre la estructura de los recursos líticos (Skarbun 2009, 2011a , 2012) permiten caracterizar cómo es la disponibilidad de materias primas, la distribución y la accesibilidad en el paisaje de las fuentes y sus relaciones espaciales con los distintos sitios arqueológicos estudiados en la localidad. Por otra parte, también se están llevando a cabo estudios sobre la funcionalidad de las fuentes, la forma en que se presentan las materias primas en las mismas y las estrategias de aprovisionamiento implementadas (Frank et al. 2007; Frank et al. 2011).

En este marco, surgieron distintos interrogantes. En primer lugar, resulta de particular interés comprender cómo se distribuyen las diferentes litologías en el paisaje de la localidad y si es esperable encontrar ciertos tipos distribuidos en diversos puntos, o si determinadas materias primas se hallan presentes sólo en sectores particulares de este espacio, lo cual puede ser hipotetizado a partir del estudio macroscópico de las rocas (Frank et al. 2011; Skarbun 2011a). Otro interrogante se refiere a si existen características diagnósticas de las rocas, posibles de identificar a partir del estudio de los segmentos delgados, que nos permitan realizar análisis de procedencia de las materias primas registradas en los sitios arqueológicos. Esta problemática ha sido discutida para otras áreas cercanas con litologías similares (Cattáneo 2004; Hermo 2008, 2009).

\section{Características de la localidad arqueológica La María}

La localidad arqueológica La María se localiza en Meseta Central de Santa Cruz, Argentina y sus coordenadas geográficas se encuentran comprendidas entre $48^{\circ} 24^{\prime} \mathrm{S}$ y $48^{\circ} 35^{\prime} \mathrm{S}$ y $68^{\circ} 47^{\prime} \mathrm{O}$ y $68^{\circ} 56^{\prime} \mathrm{O}$.

Los resultados de las investigaciones realizadas en la localidad evidencian que las sociedades pasadas ocuparon este espacio sistemáticamente, aunque con una intensidad variable, desde el final del Pleistoceno. Los sitios estratigráficos estudiados arrojaron fechados radiocarbónicos que van desde ca. 11.000 años AP para las primeras ocupaciones del área, llegando hasta el Holoceno tardío (Paunero et al. 2005). Los grupos humanos se relacionaron con el paisaje de diversos modos. Así, se ocuparon y explotaron diferentes unidades del paisaje (mesetas, cañadones, lagunas, zanjones) en los cuales existe una disponibilidad variable de recursos (materias primas líticas, pigmentos, fauna, flora) (Paunero et al. 2005; Skarbun 2011a; Paunero et al. 2011). A su vez, los registros más altos de densidad artefactual (sitios superficiales y estratificados) se encuentran en relación con unidades del paisaje asociadas con 
recursos críticos, como son los lugares con disponibilidad de agua: lagunas, ríos, vertientes, cañadones (Paunero 2009).

En este contexto, fueron utilizados de manera redundante a lo largo del tiempo los espacios reparados como cuevas, aleros y abrigos (Paunero 2009; Paunero et al. 2005), como un elemento más del paisaje dentro de la variedad de ambientes. Entre los sitios estudiados se encuentran Casa del Minero 1, Cueva Túnel y La Mesada (Figura 1), todos son multicomponentes. Su análisis muestra que existió diversidad funcional de estos espacios, evidenciando el procesamiento y consumo de fauna extinta -para momentos pleistocénicos-y actual -para momentos más recientes-; también se produjeron actividades de manufactura de herramientas líticas (con más frecuencia talla y formatización final del filo) tanto como de instrumental en hueso; y se realizó arte rupestre (Paunero et al. 2005). Las técnicas involucradas en la producción de artefactos se encontraban muy vinculadas a la estructuración de los recursos líticos locales, y a la movilidad y redes sociales de los grupos (Skarbun 2011a). En todos los componentes se registraron evidencias del uso de materias primas predominantemente locales, en algunos casos incluso los análisis macroscópicos y nuestras inferencias -realizadas a partir del análisis de las secuencias de producción de artefactos en los sitios estratigráficos y en las canteras-, indicarían que se utilizaron materias primas que se encontraban inmediatamente disponibles a los sitios (Skarbun et al. 2007; Cueto et al. 2009; Skarbun 2009, 2011a, Frank 2011; Skarbun y Frank 2010; Skarbun 2011b; Skarbun y Frank 2011).

De la misma manera, el uso de espacios abiertos estuvo relacionado con los distintos recursos circundantes, como la fauna, la flora, las materias primas líticas y los pigmentos. Para los momentos tardíos, se reconocieron sitios superficiales, que evidencian el uso residencial de sectores aledaños a lagunas o zanjones (sitios Cañadón Negro y Puesto el Frio) (Paunero et al. 2011).

\section{Estructura de los recursos líticos}

La hoja geológica Tres Cerros (Panza 1994) evidencia que las formaciones jurásicas ocupan una superficie amplia de la localidad. Entre ellas, la formación Chon Aike abarca casi el 50\% del área, mientras que las formaciones Bajo Pobre y La Matilde afloran en sectores pequeños de la misma, ocupando 5,6\% y 1,6 \% respectivamente (Skarbun 2011a y b). Por otra parte, las investigaciones arqueológicas en la región (Paunero et al. 2005), los muestreos sistemáticos en la misma (Paunero et al. 2011) y el estudio de la estructura de los recursos líticos (Skarbun 2012) indican que las materias primas líticas silíceas están disponibles y se encuentran ampliamente distribuidas en la localidad. Las mismas suelen hallarse en concentraciones primarias, que constituyen fuentes potenciales de materias primas. Estas suelen abarcan áreas aproximadas de $2000 \mathrm{~m}^{2}$, aunque en algunos casos pueden ser más grandes. También se identificaron concentraciones primarias pequeñas o materiales aislados de rocas silíceas así como crestones silicificados. A su vez, pueden encontrarse fuentes secundarias de recursos líticos de diferente origen en los zanjones y cuencas endorreicas ocupadas por barreales o lagunas temporarias.

Hasta el momento han sido identificadas 18 fuentes que se estudiaron con un grado variable de profundidad (Skarbun 2012). En general, estas son accesibles desde distintos sectores de su entorno inmediato $(0,5 \mathrm{~km})$ y del entorno de los $5 \mathrm{~km}$. Sin embargo, algunas tienen mayores costos de acceso que otras, llegando en pocos casos a poseer sectores del entorno inmediato desde donde el acceso es difícil o limitado. A su vez, si se considera la 
accesibilidad según la hidrografía, es posible que las fuentes ubicadas sobre los márgenes de las lagunas no hayan estado disponible durante el Pleistoceno final (Skarbun 2012) dado las condiciones de mayor humedad imperantes en esos momentos (Miotti y Salemme 2004; Paunero 2009). En cuanto a la relación entre las fuentes y los sitios, las investigaciones realizadas hasta el momento muestran que las primeras se encuentran a menos de $5 \mathrm{~km}$ de alguno de los sitios arqueológicos estudiados, por lo cual fueron caracterizadas como locales cercanas (Skarbun 2012).

La Cantera de Sílex de CDM (Figura 1), aflora al sur de la Localidad y se encuentra a $0,62 \mathrm{~km}$ del sitio Casa del Minero (CDM). Su estudio (Frank et al. 2007) indica que es una fuente primaria (sensu Nami 1992), compuesta por abundante material suelto producto del precipitado de un fluido (frío) sobresaturado en sílice (López 2004). Los materiales se presentan en forma nódulos. Los más abundantes poseen un diámetro menor a 20 $\mathrm{cm}$. La calidad de la materia prima es por lo general muy buena (sensu Aragón y Franco 1997), aunque varía dependiendo del grado de silicificación y de la homogeneidad de los nódulos. La corteza que los recubre varía en su grosor y en su calidad para la talla (Frank et al. 2007).

Las observaciones preliminares sobre otras fuentes de sílex, de toba silicificada y de otras materias primas silíceas -entre ellas las canteras de la María Bajo y de la Ventana- permiten postular que poseen características similares a las de la cantera de Sílex de CDM. Las mismas se refieren al tipo de fuente, a la forma de presentación y a la calidad de los materiales. Pueden encontrarse variaciones relativas a la abundancia de materiales que presentan y a las distintas proporciones de los tipos de rocas (Skarbun 2012).

Por otra parte, la cantera Bosque Petrificado se encuentra a 4,83 km de los sitios de La María Quebrada y a $13 \mathrm{~km}$ del sitio CDM (Figura 1). Los resultados preliminares de su estudio indican que se trata de una fuente primaria (Frank et al. 2011), ubicada en el sector central de una cuenca endorreica, sobre un conjunto de elevaciones. El material más abundante es la madera petrificada de origen Jurásico. Las rocas se presentan en forma de troncos silicificados de gran tamaño, bloques menores y guijarros.

La fuente Cerro el Morro se localiza a 1,64 km del sitio CDM (Figura 1), como su nombre lo indica, aflora sobre un morro que se eleva $20 \mathrm{~m}$ por encima de depósitos de antiguas playas y cordones lacustres litorales, los cuales son contiguos a la Formación La Matilde. Está compuesta por material tobáceo silicificado, de color pardo-violáceo. La materia prima se presenta concentrada como parte del mismo morro.

La fuente la María Quebrada 3, se ubica en el Cañadón de la María Quebrada (Figura 1). Aflora en forma de filón sobre la pared de una de las cuevas localizada cerca de la zona que da acceso al manto de basalto. Es un afloramiento pequeño de sílex pardo-ocre.

Tanto la Cantera de Sílex de CDM como la cantera Bosque Petrificado presentan claras evidencias de uso, donde en general se realizaron las primeras etapas de manufactura de los artefactos (Frank et al. 2007; Frank et al. 2011), y en algunos casos se formatizaron escasos artefactos expeditivos que fueron descartados allí. Los muestreos sistemáticos en la localidad y los estudios no sistemáticos de las otras fuentes (Paunero et al. 2011) también evidencian el uso de las mismas como fuentes de aprovisionamiento. De esta manera, los análisis indican que las fuentes se utilizaron como canteras o canteras taller, de manera expeditiva, ponien- 
do énfasis en las estrategias de transporte de núcleos amorfos o lascas nodulares hacia los sitios, donde habrían sido utilizados para la confección de artefactos.

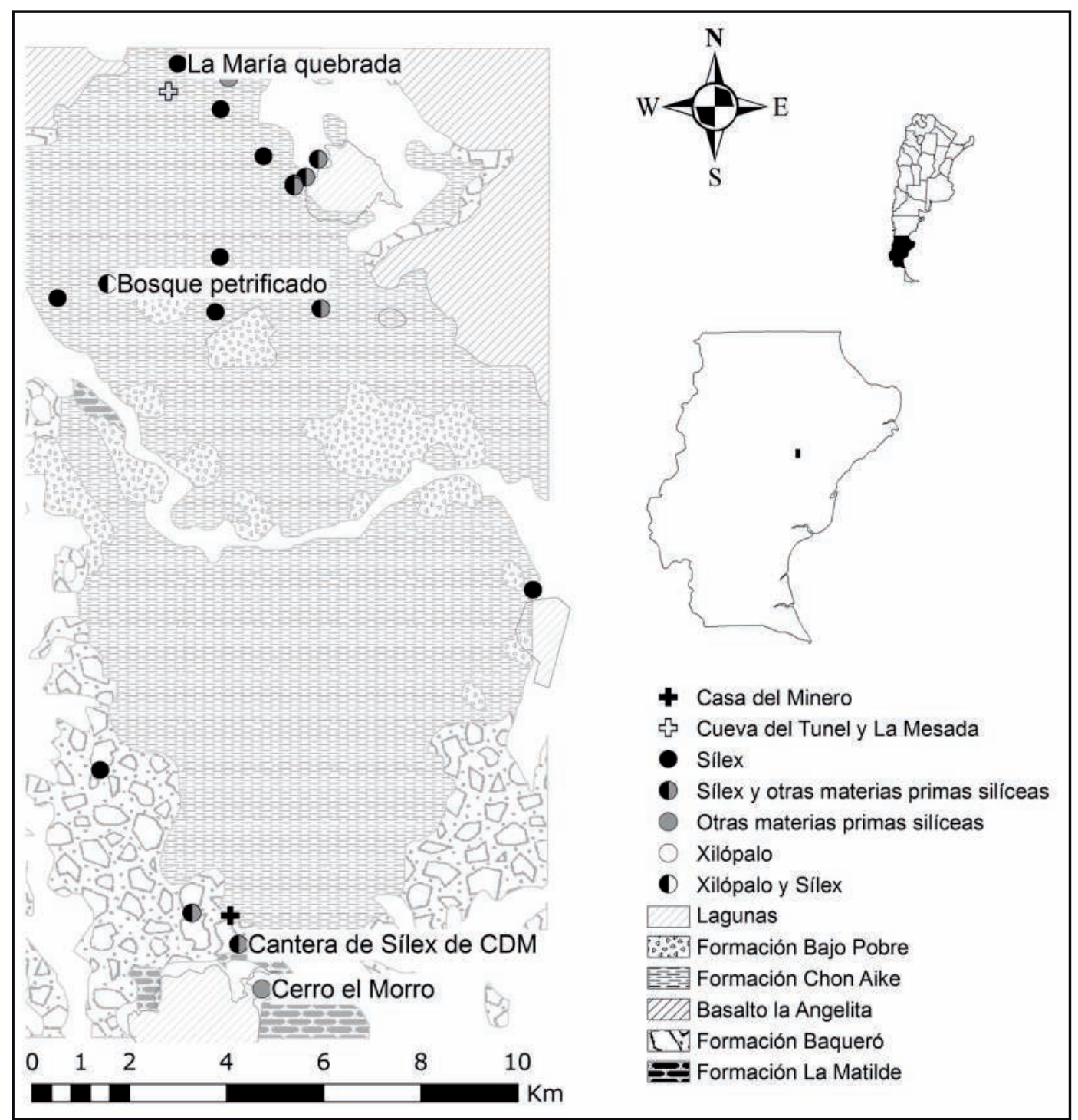

Figura 1. Mapa geológico simplificado de la Localidad Arqueológica La María mostrando la procedencia de las materias primas sobre las que se realizaron los secciones delgadas.

La distribución de los afloramientos geológicos se realizó a partir de la Hoja Geológica Tres Cerros

\section{Materiales}

(Panza 1994).

Se seleccionaron 12 muestras (Tabla 1) procedentes de cuatro de las fuentes de la localidad: 5 de la Cantera de Sílex de CDM, 1 de Cerro el Morro, 5 de la Cantera del Bosque Petrificado, y por último una muestra proveniente de La María Quebrada 3.

El estudio de las secciones delgadas fue realizado en el laboratorio de microscopía óptica del Instituto de Recursos Minerales (INREMI) de la Universidad Nacional de La Plata. Para 
ello, se utilizó un microscopio Nikon Optipho-Pol equipado con una cámara digital Nikon Coolpix P5100. Para el estudio y descripción de las muestras de origen volcánico se siguieron las recomendaciones de McPhie et al. (1993) y Nemeth y Martin (2007).

\begin{tabular}{|l|l|l|l|}
\hline$N^{\circ}$ de Muestra & $\begin{array}{l}\text { Descripción } \\
\text { Tipológica }\end{array}$ & Fuente & Descripción Macroscópica \\
\hline 1 & Núcleo & Bosque Petrificado & Xilópalo \\
\hline 2 & Lasca & Cantera de Sílex de CDM & Sílex rojo \\
\hline 3 & Núcleo & Bosque Petrificado & Volcánica silicificada roja \\
\hline 4 & Núcleo & Bosque Petrificado & Calcedonia blanca \\
\hline 5 & Núcleo & Cantera deSílex de CDM & Sílex amarillo \\
\hline 6 & Núcleo & Cantera de Sílex de CDM & Sílex rojo \\
\hline 7 & Núcleo & Cantera deSílex de CDM & Sílex amarillo \\
\hline 8 & Núcleo & Cantera de Sílex de CDM & Volcánica silicificada marrón \\
\hline 9 & Núcleo & Bosque Petrificado & Sílex rojo \\
\hline 10 & Núcleo & Cerro el Morro & Sílex marrón crema \\
\hline 11 & Núcleo & La María Quebrada 3 & Ślex marrón crema \\
\hline 12 & Núcleo & Bosque Petrificado & Sílex gris (puede ser xilópalo) \\
\hline
\end{tabular}

Tabla 1. Descripción tipológica y macroscópica de las muestras.

\section{Resultados}

A continuación se realiza la descripción microscópica de las muestras estudiadas, organizadas de acuerdo a las fuentes de la cual fueron tomadas.

\section{Muestras de la Cantera de Sílex de CDM}

Muestra 2: se trata de una lasca descripta macroscópicamente como sílex rojo. La sección delgada presenta una coloración rojiza oscura, a escala microscópica se puede reconocer una brecha en la cual tanto los clastos como el relleno presentan una composición similar representada por sílice criptocristalino (¿ópalo?) con distinto grado de tinción por óxidos de hierro, posiblemente jarosita. En general, los clastos son angulosos y se han podido reconocer al menos 4 eventos diferentes de brechamiento.

Muestra 5: es un núcleo determinado macroscópicamente como sílex amarillo. La sección delgada se presenta translúcida con una coloración amarillenta. Se trata de una roca volcánica lávica vítrea con textura afírica. La muestra presenta una textura hialopilítica a hialofiítica con un contenido de vidrio volcánico que supera el $40 \%$ en volumen. El vidrio se presenta totalmente desvitrificado en abundantes estructuras tipo litofisas (McPhie et al. 1993), que se encuentran distribuidas en forma homogénea a lo largo de todo el corte, entre las que pueden reconocerse texturas micropoiquilíticas de grano fino. Las litofisas se encuentran en su mayoría teñidas por minerales opacos. La pasta desvitrificada engloba abundantes microlitos de feldespato alcalino, cuarzo y de biotita desferrizada.

Muestra 6: es un núcleo, determinado macroscópicamente como sílex rojo. La sección delgada se presenta translúcida con una coloración anaranjada con sectores más traslúcidos e incoloros. La muestra presenta un aspecto homogéneo, caracterizado por sílice criptocristalina de aspecto isótropo (¿ópalo?) con cristalitos de minerales opacos de hábito equidimensional y dimensiones muy pequeñas. Se pueden observar cavidades rellenas de calcedonia botroidal, 
que por sectores puede estar teñida por óxidos. Asociadas a estas cavidades, pero dentro de la masa de la roca, se pueden reconocer racimos de minerales opacos a semitransparentes y de hábito acicular que se presentan sin una orientación aparente. También pueden observarse algunos parches de minerales opacos de aspecto masivo.

Muestra 7: es un núcleo determinado macroscópicamente como sílex amarillo. El corte delgado muestra un aspecto bandeado con colores castaños claros. Al microscopio se puede observar una roca sedimentaria de grano fino a muy fino, pudiéndose reconocer una alternancia de sectores de grano fino y sectores de grano muy fino. La roca muestra una silicificación fuerte y se encuentra cortada por finas vetillas de sílice de grano fino, posiblemente calcedonia. Es probable que la roca corresponda a sedimentos (posiblemente volcánicos retrabajados) que se han depositados en un ambiente de poca energía, posiblemente lacustre.

Muestra 8: es un núcleo determinado macroscópicamente como volcanita silicificada marrón. La sección delgada se presenta con aspecto homogéneo, con color castaño claro a castaño rojizo. Se trata de una roca posiblemente sedimentaria, de grano fino y con grado variable de tinción por óxidos de hierro. La muestra se encuentra silicificada y cortada por vetillas muy finas de calcedonia. Posiblemente, el origen sea volcánico retrabajado, dada la presencia de cristales de biotita parcialmente desferrizada; y el tamaño de grano fino de la roca estaría indicando un ambiente de sedimentación tranquilo, posiblemente lacustre o fluvial de baja energía.

\section{Muestras de Cerro el Morro}

Muestra 10: es un núcleo determinado macroscópicamente como sílex marrón crema. El corte delgado se presenta traslúcido con sectores irregulares fuertemente oxidados. Al microscopio presenta una textura brechosa fuertemente desdibujada por un reemplazo masivo de sílice microcristalina, posiblemente calcedonia. Por sectores se observan parches muy ricos en minerales opacos que oscurecen completamente la muestra.

Muestras de la Cantera Bosque Petrificado

Muestra 1: es un núcleo determinado macroscópicamente como xilópalo. En líneas generales la sección delgada presenta un color castaño claro, pudiéndose reconocer una textura en mosaico conformada por cristales microcristalinos de cuarzo anhedral, con geometría ameboidal y extinción ondulosa. La textura presente es indicativa de una fuerte recristalización de una litología preexistente. En algunos sectores se pueden observar estructuras relícticas con un fino bandeado que envuelven a sectores de aspecto poligonado con una textura en mosaico de mayor tamaño de grano. Posiblemente, la muestra estudiada represente un fragmento de madera fosilizada, aunque el alto grado de recristalización del cuarzo hace muy difícil su identificación, en donde los sectores bandeados podrían estar representando las paredes de las células.

Muestra 3: es un núcleo determinado macroscópicamente como vulcanita silicificada roja. La sección delgada presenta una coloración castaño rojiza muy oscura. A escala microscópica, se puede reconocer una roca volcánica cuya matriz ha sido enmascarada fuertemente por minerales opacos. La muestra se encuentra cortada por finas vetillas de cuarzo sacaroide con textura en mosaico. Se pueden reconocer fenocristales de cuarzo, también pueden observarse relictos de feldespatos que se encuentran totalmente reemplazados por un mosaico 
de cuarzo sacaroides y minerales opacos. Los minerales máficos, posiblemente biotitas, se encuentran totalmente reemplazados por minerales opacos. Todos los fenocristales presentan geometrías angulosas y fracturadas, lo cual podría estar sugiriendo que se trata de una ignimbrita, aunque el alto grado de alteración que presenta la muestra imposibilita una correcta clasificación.

Muestra 4: es un núcleo determinado macroscópicamente como calcedonia. La sección delgada se presenta translúcida con un aspecto levemente lechoso. Al microscopio la muestra es muy homogénea, pudiéndose observar un mosaico microcristalino de cristales de calcedonia con aspecto ameboidal y extinción ondulosa.

Muestra 9: es un núcleo determinado macroscópicamente como sílex rojo. La muestra presenta un aspecto traslúcido con tintes rojizos. Al microscopio se caracteriza por un delicado bandeado coloforme de calcedonia teñida por óxidos de hierro, donde alternan bandas con distinto tamaño de grano y distinto nivel de tinción por óxidos. Los opacos se presentan diseminados con grano fino o bien formando cristales de hábito dendrítico. Se pueden reconocer una vetilla de calcedonia y otra de minerales opacos cortando al bandeado, pero sin relación de corte observable.

Muestra 12: es un núcleo determinado macroscópicamente como sílex gris, posiblemente xilópalo. La sección delgada presenta un aspecto translúcido. La muestra está conformada por un mosaico de cuarzo de grano fino y aspecto elongado, que por sectores, se presenta brechado. También se reconoce una textura relíctica donde pueden reconocerse un enrejado compuesto por zonas más castañas que envuelven sectores poligonados de color más claro. Posiblemente la muestra estudiada represente un fragmento de madera fosilizada en donde los sectores con textura en enrejado estarían representando las paredes de las células.

\section{Muestras de La María Quebrada 3}

Muestra 11: es un núcleo determinado macroscópicamente como sílex marrón crema. Muestra color castaño oscuro con aspecto bandeado. Al microscopio la muestra se encuentra muy oscurecida por óxidos de hierro, los cuales tapan casi totalmente una brecha con clastos de bandeados coloformes de composición silícea micro a criptocristalina rodeados por una matriz totalmente opaca (¿ópalo con óxidos?).

\begin{tabular}{|c|c|c|c|}
\hline Grupo & Origen & $\begin{array}{l}N^{\circ} \text { de } \\
\text { Muestra }\end{array}$ & Microscopio \\
\hline \multirow{2}{*}{ A } & \multirow{2}{*}{ Vegetal fósil } & 1 & Xilópalo recristalizado \\
\hline & & 12 & Xilópalo \\
\hline \multirow{2}{*}{ B1 } & \multirow{2}{*}{ Volcánico piroclástico } & 3 & Ignimbrita oxidada \\
\hline & & 5 & Lava vítrea $\mathrm{c} /$ litofisas \\
\hline \multirow{2}{*}{ B2 } & \multirow{2}{*}{ Sedimentario } & 7 & Arenisca muy fina a pelita \\
\hline & & 8 & Arenisca fina \\
\hline \multirow{3}{*}{ C } & \multirow{3}{*}{ Hidrotermal } & 2 & Brecha de sílice microcristalina (¿ópalo?) \\
\hline & & 6 & ¿Ópalo? con calcedonia \\
\hline & & 11 & Brecha de sílice microcristalina (¿ópalo?) \\
\hline \multirow{3}{*}{$\mathrm{D}$} & \multirow{3}{*}{ Hidrotermal } & 4 & Calcedonia \\
\hline & & 9 & Calcedonia bandeada \\
\hline & & 10 & Calcedonia, (¿brecha?) \\
\hline
\end{tabular}

Tabla 2. Agrupamiento de las muestras según su similitud litológica. 
El estudio de las secciones delgadas permitió reconocer rocas volcánicas tanto lávicas como piroclásticas, cuyo origen está vinculado al hidrotermalismo, así como también restos vegetales fósiles. Asimismo, si bien el conjunto de muestras estudiadas muestran un aspecto variado, se trata de rocas comunes dentro de la Provincia Geológica del Macizo del Deseado (Panza et al. 1998).

\section{Integración de los resultados}

De acuerdo a lo observado, se agruparon las muestras por su similitud litológica (Tabla 2). El grupo A incluye las muestras que corresponden a restos vegetales fosilizados (muestras 1 y 12). El grupo B agrupa las rocas volcánicas. Éste ha sido subdividido en dos conjuntos,

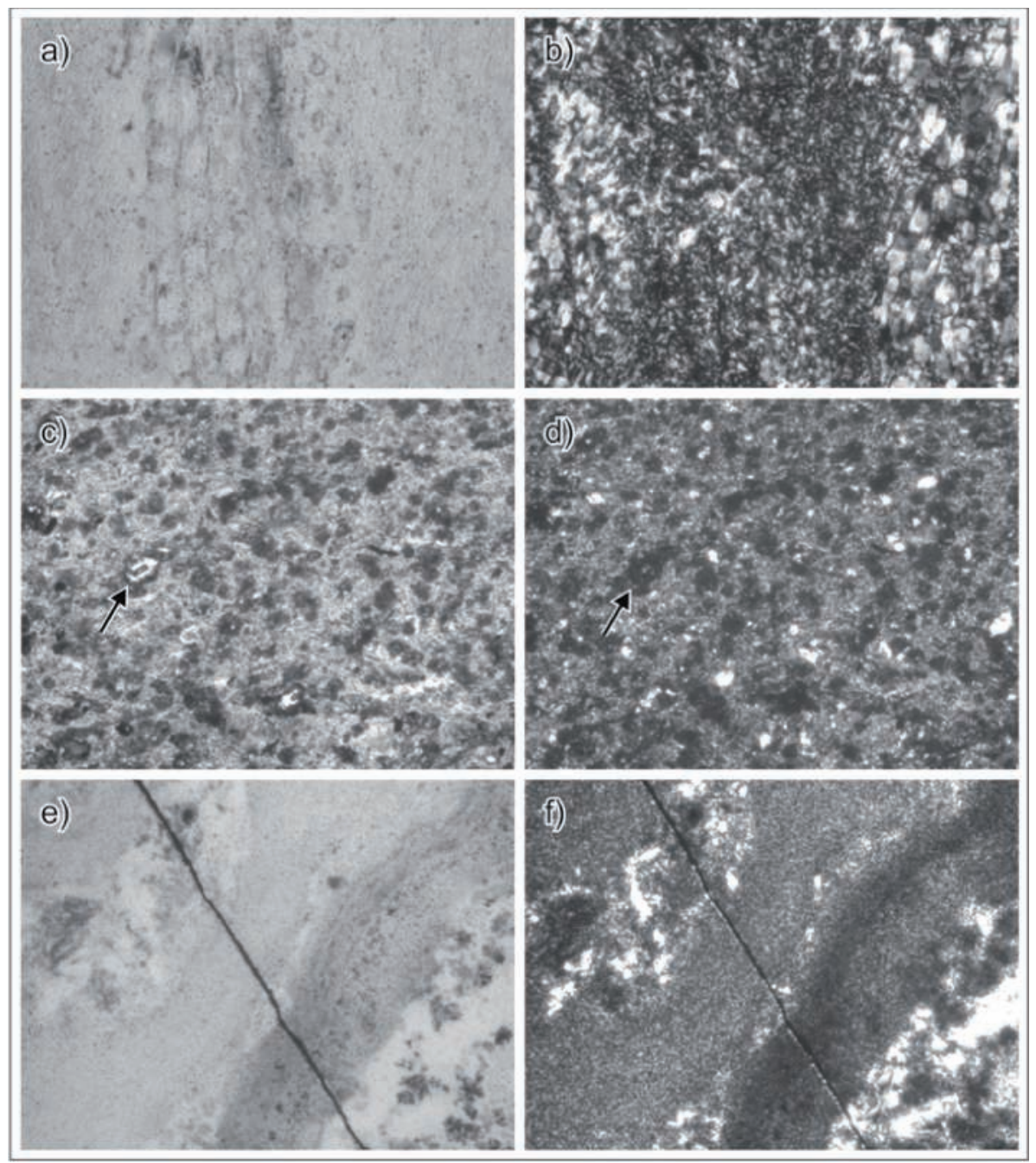

Figura 2. Microfotografías ejemplificando los principales tipos litológicos estudiados (Aumento: x50; fotografías bajo luz normal y polarizada respectivamente). Las imágenes a) y b) muestran el aspecto general de los restos vegetales silicificados pertenecientes al Grupo A (Muestra 12). Las fotos c) y d) ejemplifican algunas de las texturas reconocidas en rocas volcánicas del Grupo $B$ (Muestra 5), en este caso litofisas producto de desvitrificación (flecha). Finalmente, las imágenes e) y f) muestran un arreglo de calcedonia bandeada típico del Grupo D (Muestra 9). 
el subgrupo B1 que incluye lavas e ignimbritas pertenecientes a la formación Chon Aike (muestras 3 y 5 ) y el subgrupo B2 que incluye rocas piroclásticas retrabajadas posiblemente de la formación La Matilde (muestras 7 y 8). El grupo C reúne a todas las muestras conformadas por ópalos fuertemente teñidos por óxidos de hierro (muestras 2, 6 y 11). Finalmente, el grupo D incluye las muestras de calcedonia, que pueden presentarse con grados leves aunque variados de tinción por óxido (muestras 4, 9 y 10).

El análisis de los segmentos delgados, indica que las muestras agrupadas como grupo A se identificaron por el momento sólo en la Cantera del Bosque Petrificado (Figura 2a y b). Las muestras del subgrupo B1 se identificaron tanto en la Cantera de Sílex de CDM como en la Cantera del Bosque Petrificado, a 13,87 km de distancia entre ellas (Tabla 3, Figura 2c y d). Las muestras del grupo B2 solo se registraron en la Cantera de Sílex de CDM. Las del grupo C fueron identificadas en la Cantera de Sílex de CDM y en La María Quebrada 3, las cuales distan $18,17 \mathrm{~km}$ entre sí (Tabla 3). Por su parte, las muestras del grupo D fueron identificadas tanto en la cantera del Bosque Petrificado como en Cerro el Morro, distantes entre sí por 14,87 km (Tabla 3, Figura 2e y f).

\begin{tabular}{|l|l|l|l|}
\hline & $\begin{array}{l}\text { Cantera de Sílex de } \\
\text { CDM }\end{array}$ & $\begin{array}{l}\text { Bosque } \\
\text { Petrificado }\end{array}$ & $\begin{array}{l}\text { La María } \\
\text { Quebrada 3 }\end{array}$ \\
\hline Cantera de Sílex de CDM & - & - & - \\
\hline Bosque Petrificado & 13,87 & - & - \\
\hline La María Quebrada 3 & 18,17 & 4,75 & - \\
\hline Cerro el Morro & 1,04 & 14,87 & 19,13 \\
\hline
\end{tabular}

Tabla 3. Distancia en kilómetros entre las fuentes de procedencia de las muestras.

Por otra parte, en la cantera de Sílex de CDM se determinó la existencia de una variabilidad litológica que se corresponde con los grupos B1, B2 y C. En Bosque Petrificado se identificaron los grupos A, B1 y D, mientras que en Cerro el Morro se reconoció el grupo D y en el afloramiento de La María Quebrada el C.

\section{Discusión}

De las cuatro fuentes estudiadas, dos poseen variabilidad litológica interna (la cantera de Sílex de CDM y el Bosque Petrificado). A su vez, la variabilidad interfuente parece ser baja y la distribución de algunos de los tipos litológicos amplia. De esta manera, las lavas e ignimbritas, los ópalos y las calcedonias de la Fm. Chon Aike, se encuentran en más de un sector de la localidad, a distancias de más de $10 \mathrm{~km}$ entre sí. Esto debió tener implicancias en las estrategias de aprovisionamiento y uso de estas rocas, dado que son materias primas de calidad regular a muy buena y están distribuidas en distintos sectores. Por ello, se espera que su uso haya sido frecuente y que hayan tenido poca circulación dentro de la localidad, del mismo modo, no debieron haberse implementado estrategias para su conservación (Skarbun 2011b).

Por otra parte, solo dos grupos fueron identificados en solo un sector, el de los restos vegetales fosilizados (en el Bosque Petrificado) y el de las rocas piroclásticas retrabajadas posiblemente de la formación La Matilde (en la cantera de Sílex de CDM). Es posible que esto se deba al número bajo de muestras y debería aumentarse el mismo para asumir una escasa distribución. Sin embargo, otras líneas de evidencia estarían apoyando en principio 
esta idea. En primer lugar, el análisis macroscópico de distribución de materias primas indica que los restos vegetales fosilizados se localizan de manera abundante solo en el sector del Bosque Petrificado, aunque eventualmente podrían hallarse este tipo de rocas de manera aislada en toda la localidad. Por otro lado, considerando el segundo grupo, el análisis de la distribución de las formaciones geológicas dentro de la localidad, a partir de la Hoja Tres Cerros (Panza 1994), muestra que La Matilde aflora en sectores restringidos, que poseen una dimensión areal pequeña. En este contexto, la cantera de Sílex de CDM se encuentra a menos de $1 \mathrm{~km}$ de uno de estos afloramientos. A su vez, a $10 \mathrm{~km}$ al norte, se localiza otro afloramiento de La Matilde, también de dimensiones reducidas, donde sería posible hallar litologías similares. De esta manera, puede esperarse que las rocas piroclásticas retrabajadas del grupo B2 se sitúen en sectores restringidos de la localidad. Futuras prospecciones en el área, junto con el análisis de las secciones delgadas correspondientes, podrán aportar luz sobre estas cuestiones. Así, ambos grupos litológicos pueden considerarse escasamente distribuidos, por lo tanto se espera que hayan circulado dentro de la localidad, pudiéndose encontrar frecuentemente en sitios arqueológicos cercanos a la fuente, pero también, en los sectores más alejados (Skarbun 2011b).

A manera de conclusión, las muestras estudiadas corresponden a variaciones litológicas de la formación Chon Aike y posiblemente también a la formación La Matilde (Panza et al. 1998), es decir, representan litologías típicas observadas en casi toda la región del Deseado. De esta manera resulta dificultoso poder establecer una relación directa entre el material lítico arqueológico y probables afloramientos de procedencia, mediante estudios de secciones delgadas.

\section{Agradecimientos}

Este trabajo fue realizado como parte del plan de trabajo de beca postdoctoral otorgada por CONICET de la Dra Skarbun, y en el marco del proyecto "Investigaciones arqueológicas en la Meseta Central de Santa Cruz: Pasado humano y comunicación" N553. SeCyT. UNLP, dirigido por el Lic. Rafael Paunero, a quien agradecemos su apoyo. También agradecemos al equipo del proyecto por las tareas de campo y de laboratorio. Las secciones delgadas fueron realizadas por el Lic. Ricardo Ponti a través del subsidio a Tesistas 2008 otorgado a Skarbun por la FCNyM, UNLP. El estudio de las secciones delgadas se realizó en el laboratorio de microscopía óptica del INREMI. Agradecemos al Dr. Ariel Frank la lectura del manuscrito y la traducción al inglés del resumen. A la familia Behm por la logística y por permitirnos realizar nuestras investigaciones en la Estancia La María. A la comunidad de San Julián y sus autoridades, por recibirnos afectuosamente y brindarnos la ayuda para realizar nuestras tareas.

\section{Bibliografía citada}

Andrefsky, W. J.

1994 The geological occurrence of lithic and stone tool production strategies. Geoarchaelogy: An International Journal 9 (5): 375-391.

Aragón, E. y N. V. Franco

1997 Características de rocas para la talla por percusión y propiedades petrográficas. Anales del Instituto de la Patagonia. Serie Ciencias Humanas 25: 187-199.

Bleed, P.

1986 The optimal design of hunting weapons: maintainability or reliability. American Antiquity 51(4): 737-747. 
Cattáneo, G. R.

2004 Desarrollo metodológico para el estudio de fuentes de aprovisionamiento lítico en la meseta central santacruceña, Patagonia argentina. Estudios Atacameños 28: 105-119.

Cueto, M. E., R. S. Paunero y A. S. Castro

2009. La aplicación del análisis funcional sobre el conjunto artefactual lítico del componente temprano del sitio Casa del Minero 1 para la determinación de operaciones técnicas. Trabajo presentado en XVIII Congreso Nacional de Arqueología Chilena. 5 al 9 de Octubre de 2009. Museo de Historia Natural de Valparaíso, Valparaíso, Chile.

Frank, A. D.

2011. Tratamiento térmico y manejo del fuego en sociedades de cazadores recolectores en la Meseta Central de Santa Cruz. Tesis Doctoral en Preparación, Facultad de Ciencias Naturales y Museo, Universidad Nacional de La Plata.

Frank, A. D., F. Skarbun y M. F. Paunero 2007 Hacia una aproximación de las primeras etapas de reducción lítica en el Cañadón de la Mina, Localidad Arqueológica La María, Meseta Central de Santa Cruz, Argentina. Magallania (Punta Arenas) 35: 133-144.

Frank, A. D., F. Skarbun y M. E. Cueto

2011 Caracterización de una fuente de xilópalo: el caso del Bosque Petrificado de la Localidad Arqueológica La María. Trabajo presentado en VIII Jornadas de Arqueología de la Patagonia, Malargüe.

Hermo, D. O.

2008 Los cambios en la circulación de las materias primas líticas en ambientes mesetarios de Patagonia. Una aproximación para la construcción de los paisajes arqueológicos de las sociedades cazadoras-recolectoras. Tesis doctoral inédita, Facultad de Ciencias Naturales y Museo, Universidad Nacional de La Plata.

2009 Estructura de los recursos líticos y paisajes arqueológicos en el Nesocratón del Deseado (Santa Cruz, Argentina). Arqueología Suramericana 5: 178-203.

López, R.

2004 Informe Sobre Afloramientos Rocosos de Interés Arqueológico en Estancia La María, Santa Cruz. M.S.

Mcphie, J., M. Doyle y R. Allen

1993 Volcanic Textures: a guide to the interpretation of textures in volcanic rocks. CODES. University of Tasmania.

Miotti, L. L. y M. C. Salemme

2004. Poblamiento, movilidad y territorios entre las sociedades cazadoras-recolectoras de Patagonia. Complutum 15: 177-206.

Nami, H. G.

1992 El subsistema tecnológico de la confección de instrumentos líticos y la explotación de los recursos del ambiente: una nueva guía de aproximación. Shincal 2: 33-53. 
Nelson, M.

1991 The study of technological organization. Archaeological Method and Theory, volumen 3, (ed. por M. Schiffer), pp 57-100. University of Arizona Press, Tucson.

Németh, K. y U. Martin

2007 Practical Volcanology. Occasional Papers of the Geological Institute of Hungary 207: 221.

Pankhurst, R., P. Leat, P. Sruoga, C. Rapela, M. Marquez, B. Storey y T. Riley

1998 The Chon Aike province of Patagonia and related rocks in West Antartica: a silicic

large igneous province. . Journal of Volcanology and Geothermal Research 81: 113-136.

Panza, J. L.

1994 Descripción de la Hoja Geológica 4969-II. Tres Cerros Escala 1:250.000. Provincia de Santa Cruz. Boletin 213. Servicio Geológico Nacional, Buenos Aires.

Panza, J. L., G. Marín y M. Zubia

1998 Hoja Geológica 4969-I, Gobernador Gregores, escala 1:250.000, provincia de Santa Cruz.

Servicio Geológico Minero Argentino, Boletín 239, Buenos Aires.

Paunero, R. S.

2009 Fogones, conjuntos líticos y funcionalidad en el componente pleistocénico del sitio Cueva 1 de Cerro Tres Tetas, provincia de Santa Cruz. Publicaciones del XIV Congreso Nacional de arqueología Argentina, Tomo II. Capítulo XIV: Tecnología y arqueología: enfoques en la reconstrucción de los modos de producción y uso de bienes en sociedades indígenas. pp 419-428. Facultad de Humanidades y Artes, UNR. Rosario. 2009. La colonización humana de la meseta central de Santa Cruz durante el Pleistoceno final: indicadores arqueológicos, referentes estratigráficos y nuevas evidencias. En M. C. Salemme, F. Santiago, M. Alvarez, E. Piana, M. Vazquez y M. E. Mansur (eds), Arqueología de Patagonia: una mirada desde el último confín: 85-100. Ushuaia. Editorial Utopías.

Paunero, R. S., A. D. Frank, F. Skarbun, G. Rosales, G. Zapata, M. E. Cueto, M. F. Paunero, D. G. Martinez, R. López, N. Lunazzi y M. Del Giorgio

2005 Arte Rupestre en Estancia La María, Meseta Central de Santa Cruz: Sectorización y contextos arqueológicos. Relaciones de la Sociedad Argentina de Antropología XXX: 147-168.

Paunero, R. S., N. Lunazzi, C. Valiza Davis, M. Del Giorgio, M. Paunero y J. Pifano 2011. Estudio de sitios a cielo abierto en meseta y costa de Santa Cruz: La María y Península de San Julián. VIII Jornadas de Arqueología de la Patagonia Malargüe

Schalamuk, I. B., M. Zubia, A. Genini y R. R. Fernández

1997 Jurassic epithermal Au-Ag deposits of Patagonia, Argentina. Ore Geology Reviews 12: 173-186.

Skarbun, F.

2009 Análisis de los conjuntos líticos del sitio La Mesada, Localidad Arqueológica La María, Meseta central de Santa Cruz. Arqueología de Patagonia: una mirada desde el último confin, volumen 2, (ed. por M. C. Salemme, F. Santiago, M. Alvarez, E. Piana, M. Vazquez y M. E. Mansur), pp 1177-1194. Editorial Utopías, Ushuaia. 
2011a La organización tecnológica en grupos cazadores recolectores desde las ocupaciones del Pleistoceno final al Holoceno tardío, en la Meseta Central de Santa Cruz, Patagonia. BAR International Series 2307. Archaeopress. Publish of British Archaeological Reports, Oxford. 2011b Variability in lithic technology strategies of early human occupations from Central Plateau of Santa Cruz, Argentina. Current Research in the Pleistocene. Special volume: En prensa.

2012 Estructura de los recursos líticos en el sector central de la Meseta Central de Santa Cruz, Argentina. Intersecciones en Antropología: Enviado.

Skarbun, F., A. D. Frank, M. E. Cueto, M. F. Paunero y G. Rosales 2007. Análisis de la tecnología lítica del Sitio Casa del Minero 1, Meseta Central de Santa Cruz. Arqueología de Fuego-Patagonia. En F. Morello, A. Prieto, M. Martinic y G. Bahamondes (eds), Levantando piedras, desenterrando huesos... y develando arcanos: 589-600. Punta Arenas, Chile. Centro de Estudios del Cuaternario Antártico (CEQUA).

Skarbun, F. y A. D. Frank

2011. Organización espacial intrasitio durante el Pleistoceno final en la Meseta Central de Santa Cruz. Evidencias del sitio Casa del Minero 1. Relaciones de la Sociedad Argentina de Antropología XXXVI: 289-313. 